\title{
Chemical toilet for persons with disabilities: proposal for an urban furniture affordable
}

\author{
Tavares, Ademario Santos ${ }^{\mathrm{a}}$ and Montenegro, Glielson Nepomuceno ${ }^{\mathrm{b}}$ \\ ${ }^{a}$ Federal University of Campina Grande. Address: Rua da Cruz, $18-1^{\circ}$ andar-MB Jesus, BO 55008-280, \\ Caruaru-Pernambuco, Brazil. (81) 9645-7928. \\ ${ }^{\mathrm{b}}$ Federal University of Campina Grande. Address: Rua Aprigio Veloso, 882 Bloco BO 58109-970 - Campina \\ Grande-Paraiba, Brazil. (83)3310-1132.
}

\begin{abstract}
Street furniture is an important element to the social and democratic life in the cities. In this case, public restrooms must be available to practically all kinds of citizens that inhabit the city. However disabled people have many difficulties in using the existing models, particularly public chemical toilets. Through a design project, a new proposition for a public chemical toilet addressed to wheelchair users was conceived. In this way, the main aspect of this work refers to the actual participation of the disabled expressing their opinion through interviews and usability analysis as well as the observation on technical recommendations for accessibility set by ABNT. Ergonomics analysis and Usability considerations were of great importance to the conclusion of this project.
\end{abstract}

Keywords: ergonomics, accessibility, public WC, design methodology

\section{Introduction}

Urban design is an important aspect for the quality of life of urban population in the cities which includes, among other questions, the adequate distribution of urban elements that put together its complex infrastructure. The more adapted a city is to all its citizens, the better the benefits that the infrastructure will promote to all of them. In this context we can include the street furniture. According to Brazilian technical standards NBR 09283 [2], the street furniture can be defined as:

Objects, elements or small buildings that are part of urban landscape, having or not an utilitarian nature, set in public or private spaces according to legal statements of public administration.

Street furniture promotes the integration, socialization and also democratization of urban spaces because they belong to all citizens. Unfortunately, many cities around the world don't provide an appropriated infrastructure to their population making its integration very difficult aspect. According to Pereira [9], a research undertaken in England revealed that $96 \%$ of women don't use public rest- rooms due to problems related to lack of hygiene and appropriated structure.

Del Rio [4] emphasizes that:

[...] somehow and within a certain level of intensity our behavior and our urban actions are influenced by built environment around us. We can state that environment suggests, facilitates, repress or defines different kinds of behaviors, in other words, it functions like a positive or negative catalyser.

If we could divide city population in small groups, the disabled group certainly would interact in a very little proportion to the city due to their physical limitations. In accordance with Rozicki [10], OMS classify the existing physical limitations in: handicap, blinded, mental, deafness and multiple restrictions (two or more associated physical limitations). Among those, problems related to accessibility in the city are of great concern to those whose physical restrictions are part of their everyday life.

When city events of great proportions that attract a huge number of people take place, such as carnival in Brazil, that kind of problem can be clearly observed.

* Corresponding authors: demasantosdesigner@gmail.com glielson@ddi.ufcg.edu.br. 
Though such events have an intention to promote part of national culture and entertainment for all the participants, encouraging interaction among people no matter its beliefs, social, physical and racial conditions, the number of disabled in those events are expressively low as a result of structural gaps in the built environment mainly connected with lack of physical security, accessibility, medical aid, proper lodging, food and amusement. When the necessary conditions are not pleasingly guaranteed where the event takes place, disabled participants don't interact neither with the built environment nor other people, being segregated thus.

Professionals and institutions responsible for urban planning and development of industrial products, such as industrial designers, may change their way of thinking and acting about the increasing legislation focusing social inclusion for disabled people along with accessibility discussions and inclusive design principles.

The fundamental principle that conducted the development of this study is related to the usability of an urban element of street furniture that influences the presence and participation of people in crowded places: chemical toilets. Generally they are set in areas where the existing ones don't supply the effective participants' demands for that kind of service, such as large shows in open spaces, buildings sites or touristic spots where historical and architectural preservation are compulsory requirements. They also are directed to seasonal events due to their assembly facilities systems.

\subsection{Study delimitation}

This study took into consideration the general characteristics and physical urban structure of Brazilian cities. As an urban element, its context is very complex to be put under analysis because a series of urban dynamic factors are involved. In the words of Clara Greed [6], the analytical context of an urban element could be divided into three scales:

- Large - refers to global situation, of national and large scale, besides those factors that influences the decision-making process concerning the situation of hygiene as a whole;

- Medium - the intermediate level, enclosing local area and its neighborhood. It is related to the city and those places where public toilets may be settled;

- Micro - it concerns to private matters and so it is very detailed. It includes, for instance, self experience, problems linked to construction factors, rience, problems linked to construction factors, maintenance, vandalism, etc.

Those levels are integrated, and in changing one aspect of context may cause a change to the others. This study rests upon the micro level once it is referred to the development of an industrial product, that is, a public chemical toilet addressed to disabled people in wheelchair.

\subsection{Ergonomics}

Ergonomics has a very important role in this work because its methods, techniques and principles establish a link between the user (disabled in wheelchair) and the product (public chemical toilet). According to Iida [7], Ergonomics can be considered as a multidisciplinary science, in which the relations among men and their activities are the research object, including the equipments, environment and limitations inherent to human being. ABERGO [1] states that Ergonomics may be seen as a scientific discipline which aims human's well-being and a global performance of a system through the application of theories, principles and methods.

\subsection{Usability}

Soares [11] establishes that ergonomically designed products consider a greater range of users. The product usability is an important requirement which will ensure a deep interaction between the user and the product, giving him/her more autonomy, comfort, performance and satisfaction when usability is detailed studied and correctly applied to an object.

During this work we interviewed some disabled in wheelchair so they could tell us about their self experiences related to the usability of a chemical public toilet and contribute to the development of an adequate product specifically intended to them. Ergonomics Participative techniques were used once it takes into consideration the users' opinion, on the words of Fialho and Santos [5].

At the same time, some existing models of accessible public toilets were analyzed under the application of accessibility technical standards.

\section{Design methodology}

Developing a new product, requires the use of a proper design method that may integrate and reunite all the necessary data referring that product in a sys- 
tematic manner. It is necessary to organize and analyze all the acquired information that may contribute to an effective and appropriated solution to the existing problem.

\subsection{Design steps}

The methodology used to develop this product was organized into four principal steps and are included in the final technical report [12].

- Step 1 - Data collection

* Photo record of chemical public toilets avaliable in Brazilian market, including conventional and "accessible" models;

* Bibliographic and web searching for papers, catalogs, technical magazines and analysis on technical Brazilian standards;

* Interviewing Associação dos Deficientes do Compartimento da Borborema (ASDECB) supervisor, in Paraíba;

* Interviewing forty ASDECB disabled members;

* Data collection from businessmen that provide articles to disabled such as wheelchairs, crutches, etc.

- Step 2 - Data Analysis

* Users' profile analysis, including habits, behavior, educational level, entertainment preferences, etc;

* Usability analysis on disabled behavior and movements simulations in an accessible toilet model, taking into consideration biometric standards and ABNT regulations;

* Analysis on Product-environment interaction in the northeast of Brazil;

* Structural and functional analysis of standard elements used in the making of an accessible chemical toilet;

* Morphological analysis of geometric elements that generate the internal and external structure of a standard chemical toilet;

* Comparative analysis among similar products of the same functional category;

* First Conclusions to define basic requirements to the product design.

Steps one and two were taken simultaneously.

- Step 3 - Preliminary design

* Based upon structural, functional and morphological analysis, a list of requirements, parameters, constraints and sub-factors were organized;
* Sketching process using creativity techniques;

* Analyzing and selecting among the proposed solutions for further detailing and improvements;

* Selecting structural and functional components available in the market specifically designed to disabled products.

- Step 4 - Final design

* Detailing functional and structural systems, specifying components and parts, improving the final layout;

* Detailing technical aspects of the product: materials, production processes, assemblage, surface finishes;

* Design report containing all methodological steps, photos, graphics, tables and technical data;

* 3D Virtual Modeling detailing the proposed modifications and technical improvements;

* Mockup in small scale;

* Recommendations and final conclusions.

The methodological steps taken to develop such product design demonstrate the complexity and multidisciplinary aspects involved in that process. It means that an Industrial Designer must always be in touch with other fields of knowledge and researches such as Production Engineering, Material Engineering, among others. Ergonomics is in this context and this paper is based upon that. As a way to present this project regarding users' demands, usability questions will be subsequently detailed while technical and production ones may be set aside.

\subsection{Accessible toilets usability: regulations and opinions}

Four topics were defined to guide this project in order to develop a series of design tasks:

\subsection{1 - Analysis of accessible toilets available in $\mathrm{Pa}$ - raíba}

Several different analysis were taken in an accessible chemical toilet chosen as a sample to understand how the product functions along its components, parts and technical systems, verify its importance to society as well as get used to its structure. By those analysis, was possible to determine the technical requirements and parameters, contraints and sub-factors that were determinant to develop a more functional and secure project. The study took place in João Pessoa and Campina Grande (ASDECB house), two mayor cities of Paraíba, Brazil, where, 
two accessible toilets were found and selected as samples to the proposal analysis.

\subsection{2 - Interviewing disabled people in wheelchair}

During product development, industrial designers must take into consideration users' demands and look for the appropriated solutions that will fulfill the users' needs, since their self experiences are important to adequate the product design to disabled ones.

Based upon that concept, forty associates of ASDECB were asked to answer some questions referring the usability of chemical toilets. The group consisted of disabled individuals with amputated limbs that use crutches as well as wheelchairs.

All the interviewees expressed their embarrassment when using a public toilet and some of them had never used a chemical one. According to the answers, some situations were frequently reported:

- The toilet is unsuitable for the disabled because its internal space does not provide the sufficient area to move around it.

- Lack of security to enter, to leave and to move inside the toilet.

- Lack of hygiene inside the toilet. We must be aware that the disabled, needs to touch the inside structure and its components to facilitate the his/her mobility.

- Lack of privacy. Public toilets are used by all citizens and those who are not disabled sometimes are ruthless when using them, jeopardising hygiene inside the toilet as well as the necessary mobility to those who have physical restrictions. An exclusive toilet intended to disabled people seems to be the answer to the problems faced by them.

After analyzing disabled' answers and opinions, we came to the conclusion that the existing public toilets in João Pessoa and Campina Grande do not provide the necessary conditions to be used by disabled citizens.

\section{3 - Applying technical regulations for accessibility to urban elements/street furniture}

Brazil has its own technical regulations regarding accessibility in urban spaces that is the NBR 9050 [3] elaborated by Brazilian Accessibility Committee (ABNT/CB-40). This regulation makes available the necessary support to make secure, comfort and functional a built environment, equipment or urban element that may be used by a disabled citizen.
A chemical public toilet and a masonry one were subject of structural and usability investigation to verify if the standards recommendations on NBR9050 effectively were considered by designers and builders. According to the results, we tried to observe the accomplishment of the regulations as well as the disabled' levels of satisfaction and fulfillment of their needs.

To prevent distortions and misinterpretations on the existing technical recommendations regarded internal dimensions to public toilet designs, we adopted two different standards to support our analysis of the toilets which could be found in Paraíba, Brazil. It was not our intention to the most accessible toilet or one that could strictly fit the technical regulations, on the other hand, the analyses was carried out on the available models.

These analyses were based upon a comparison among the following topics:

- Constructive recommendations and interior layout to accessible public toilets, concerning technical data and NBR 9050 proceedings including metrical distances and types of components and systems, manipulation ranges, material finishing, etc.

-Usability, structure, internal accessories and metrical dimensions of a masonry public toilet, considered as accessible.

- Usability, structure, internal accessories and metrical dimensions of a chemical public toilet, considered as accessible.

To hold the results and approximate them closely to reality, a systematic observation on the performance of a disabled man in wheelchair in an accessible toilet was done. Based on this assumption, we could obtain a more reliable data to the research, organizing them afterwards, in tables related to structural analysis of the two accessible toilets, technical analysis concerning NBR9050 and usability analysis by the toilet user.

\section{4 - Analysis of an accessible toilet used by a dis- abled}

NBR9050 may be considered of theoretical and pragmatic features once it holds important information that determines some criteria and technical parameters concerning the construction and adaptation of public buildings and furniture emphasizing accessibility. However, we are aware that practical application of those recommendations is, sometimes apart from real conditions and demands faced by disabled. 
In Figure 1 we can see three images demonstrating the movement of the disabled in a public toilet, according to theory. The other two images show the real situation that occurs when a disabled man in wheelchair needs to use the toilet, moving very differently from those ones indicated in the technical norm.
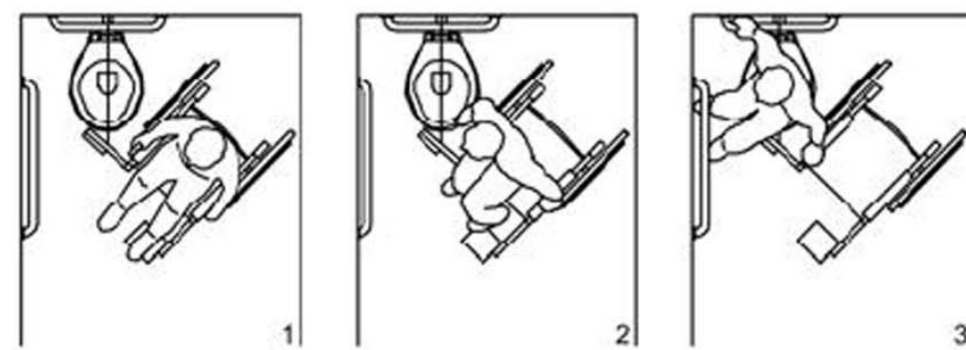

3
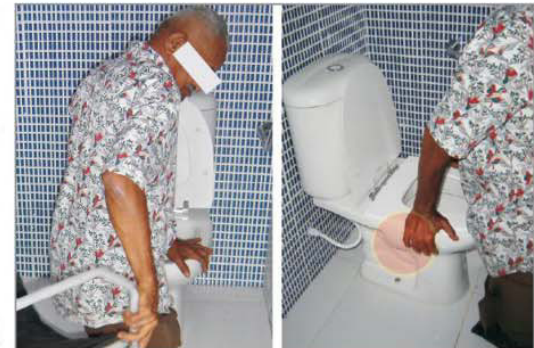

Figure 1. Disabled man in wheelchair climbing up to the toilet according to NBR (Left); and during usability analysis (in practice (Right)

The movements performed by a disabled person inside a toilet can be considered of complexity due to his/her physical limitations and the internal layout of the place. In this situation, the recommendations of NBR9050 may not completely fit the needs of the disabled, because there are a very large number of different usability scenarios.

So, we came up with the idea of observing a disabled in wheelchair to determine the actions he undertakes when using the public toilet (an usability analysis). As the disabled man in wheelchair simulates to use the toilet, it was possible to get some data that are not considered by the NBR9050. In this way we succeed when comparing both theoretical and practical recommendations.

The actions were arranged in 11 different steps/tasks, listed as below:

- Step 01: approaching the public toilet and opening the door;

- Step 02: entering the toilet;

- Step 03: moving around to get used to the environment (motion and orientation);

- Step 04: closing and locking the door;

- Step 05: coming near to the toilet and preparing to climb on it;

- Step 06: sitting on the toilet;

- Step 07: using the toilet and doing one hygiene;

- Step 08: getting down the toilet;

- Step 09: washing the hands;
- Step 10: unlocking and opening the door;

- Step 11: leaving the toilet and closing the door.

During the accomplishment of 11 steps, 31 NBR9050 recommended actions or situations were done.

Those actions are related to distances, sizes, materials, components thickness, sequences of accesses and available interior space of the public toilet. Some of the actions were repeated but not mentioned. In a general way, the results have shown that there are differences among the NBR recommendations and the disabled needs.

Both public toilet samples examined, presented the same kind of problems, such as:

Lack of: International symbol for accessibility; resistant covering to door impacts; horizontal support bar; free approaching area to the toilet and washbasin and emergency signaling device; support bars inadequately located; inadequate length to the support bars.

While masonry toilet has fulfilled 17 of the 31 analyzed actions, the chemical toilet dealt with only 11 of the technical recommendations, which means that $54 \%$ of the items recommended by the NBR were positively achieved by the masonry toilet, while merely $35 \%$ by the chemical toilet.

The results were organized in a table and the positive and negatives aspects (graphically represented in blue and red dots, respectively), helped elaborating improvement strategies for the new product design. The Table 1 presents part of the final table. 
Table 1

Comparing NBR recommendations to usability in accessible toilets

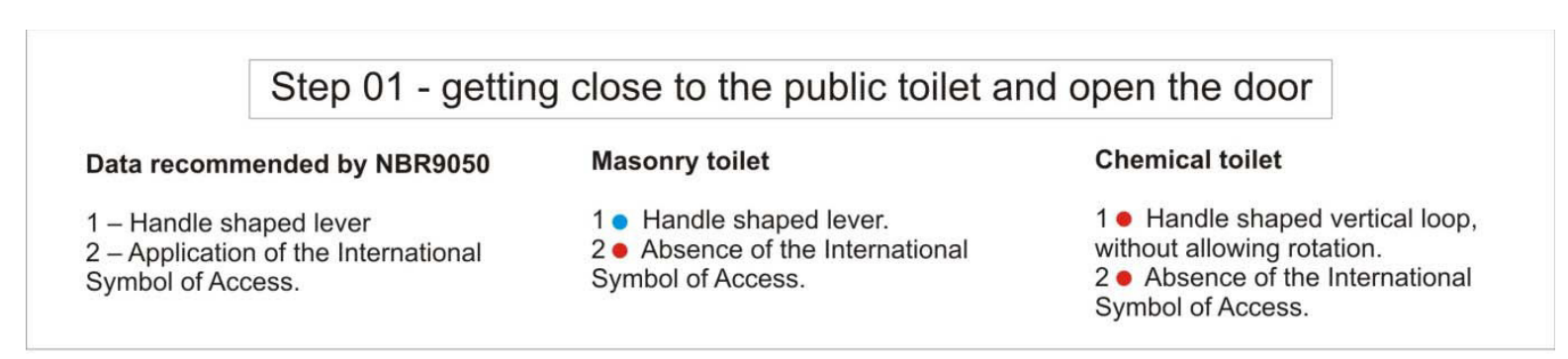

According to Martins and Baptista [8], as a normative reference, Brazil owns one of the most advanced technical regulations to accessibility in the world, though the observed situation of both toilets is very worrying once the effective application of the NBR recommendations does not regard that at all, as we found out at the end of this research. Martins and Baptista [8] quote:

The standard regulation must constitute a reference media to ensure environmental quality, ensure individuals the right to move and the right to enjoy the spaces according to the activities that will be unfold.

When designing a product, it is important to take into consideration the criteria and the parameters defined by specific technical regulations, as a way to assure its functionality and performance preventing undesirable situations that could cause physical and psychological constraints.

\section{A new product, according to necessities}

Having all the necessary information, pre-design and design phases have begun. In the developing proposal, five of the technical requirements were chosen to be improved. New configurations and components were defined based on the problematic features observed in the previous analyzed toilets, submitting each one of the requirements to the NBR9050 technical recommendations and, above all, to the opinions of the disabled.

- Visibility

* Setting the International Symbol for Accessibility in all external surfaces, in fluorescent painting.

* Braille and touchable maps on strategic parts as the door and the interior of the toilet. This aspect helps blind people to use the toilet as well.

- Security

* Solar energy and rechargeable battery integrated security system. A system controls the emergency alarm, lighting, ventilation and unlocks the door.

* Support bars all over the internal structure of the toilet, including double bars and articulated ones in the urinal.

* Wider seat with coupled bars and approaching area in order to make easier the transferring from wheelchair to toilet structure, preventing the disabled from touching the surface of the toilet or the floor.

* Urinol in order to avoid using the toilet and the excrements box only. Consequently, the toilet will be less used.

- Systems

* Exclusively used by disabled, preventing usage by others without physical limitations. Only those people in charge for the maintenance and cleaning are authorized to enter the place.

* Energy storage system through rechargeable batteries and solar energy caption.

* Presence Integrated system, will put lighting, ventilation and security alarms to work when activated by the user as he/she enters the toilet.

- Hygiene

* Alcohol gel near the toilet and the door to encourage and facilitate personal hygiene.

* Seat cover on the top of the toilet and on the top of excrements box along with cleaning chemical solutions.

- Comfort 
* Cushioned seats.

* Bars coated with rubber to make hanging easier.

* Simplicity working systems components, such as levers and buttons.
The figure 2 shows some images of the virtual model (made with 3D software). Details are reported in the final technical report.
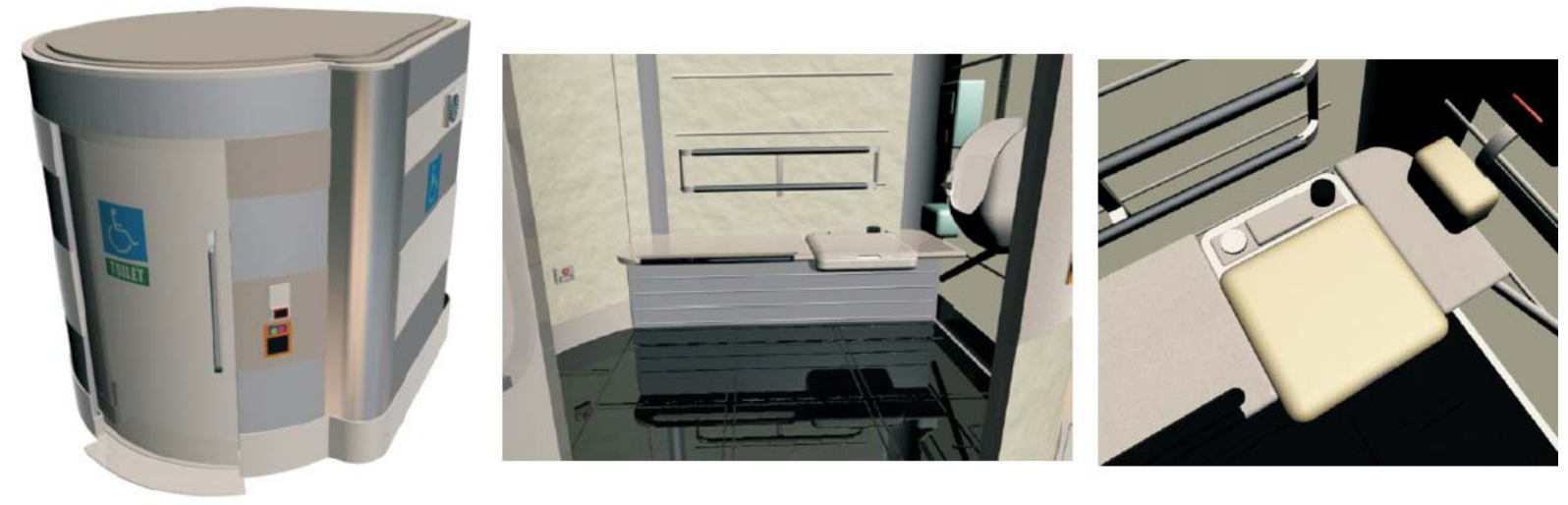

Figure 2. Images of the new chemical toilet for disabled users

\section{Conclusions}

This Project clearly helped out to show the importance of searching for data near users of a specific product. During the research there had been a sense of confidence, discipline and commitment among the designer and the interviewees. Those disabled who participated this research had the opportunity to express their opinions, ideas and information. Great expectations took place during the making of this project in order to conclude it and design a new product that would be exclusively addressed for those who have physical limitations.

Even though there are specific technical regulations for this kind of artifact and a few similar models for the proposed product, the users' opinions are the most important aspect to be considered. Disabled people are the only ones who really know the difficulties, needs and expectations concerning the usage of a product that is intended to them. Regardless an existing pattern in a sequence of tasks to enter, use and exit the public toilet, there is a great diversity of users and there are many different situations that may happen in the interior of the public toilet. In this case, designing a specific product for disabled people was of great importance to promote autonomy, privacy, security, comfort and hygiene.

On the other hand, it is very disappointing to find out that both models of "accessible" toilets available in the market intended to incapacitated person do not correspond to the recommendations of the technical regulation for accessibility. It is necessary to follow unconditionally the parameters and methods defined by technical norms in order to obtain a better usability, security and comfort. It is more important to really be accessible than just bearing an "accessible toilet for disabled" title which does not fulfill the needs of their users. Designing more accessible products is the main role of the industrial designer and ergonomics.

\section{References}

[1] ABERGO. O que é Ergonomia? Ergonomia. Disponível em: http://www.abergo.org.br/. Acesso em: 01 fev. 2010.

[2] ASSOCIAÇÃO BRASILEIRA DE NORMAS TÉCNICAS. NBR 09283: Mobiliário Urbano. Rio de Janeiro, 1986.

[3] ASSOCIAÇÃO BRASILEIRA DE NORMAS TÉCNICAS. NBR 9050: Acessibilidade a Edificações, Mobiliário, Espaços e Equipamentos Urbanos. Rio de Janeiro, 2004.

[4] Del Rio, V. Introdução ao desenho urbano no processo de planejamento. São Paulo: Pini, 1990.

[5] Fialho, F. A. P. and Santos, N. dos. Manual de Análise Ergonômica no Trabalho. 2.ed. Curitiba: Genesis, 1997.

[6] Greed, C. Inclusive Urban Design - Public Toilet. New York: Architectural Press, 2003.

[7] Iida, I. Ergonomia: projeto de produção. São Paulo: E. Blucher, 2001.

[8] Martins, L.B. and Baptista, A.H.N. A Ergonomia do Ambiente Construído e a NBR9050 aplicada ao ambiente urbano. ENCONTRO NACIONAL DO AMBIENTE CONSTRUÍDO, 1, 2007, Recife. Anais digitais. 
[9] Pereira, L.V. Critérios de Usabilidade para design de banheiros públicos. Congresso Internacional de Pesquisa em Design, 3, 2005, Rio de Janeiro.

[10] Rozicki, C. Deficiente e a participação nas esferas da vida em sociedade. Revista Espaço Acadêmico Disp. em: $<$ http://www.espacoacademico.com.br/022/22crozicki.htm> Acesso em: 22 de nov. de 2008
[11] Soares, M. M. Ergonomia: Princípios, Métodos e Técnicas Universidade Federal de Pernambuco: Recife, 2009. Curso de Extensão em Ergonomia. 01 de set. 2009 a 31 de out. 2009. Notas de aula.

[12] Tavares, A.S. Desenvolvimento de Banheiro Químico para Portadores de Necessidades Especiais de Locomoção. 2009 106f. Trabalho de Conclusão de Curso (Graduação) Universidade Federal de Campina Grande, Campina Grande, 2009 . 